\title{
CASE REPORT \\ Bacillary angiomatosis: A rare finding in the setting of antiretroviral drugs
}

\author{
M C Madua, MB ChB, FCP (SA) \\ Rob Ferreira Hospital, Nelspruit, South Africa \\ Corresponding author: M C Madua (chasneyza@yahoo.com)
}

\begin{abstract}
An HIV-positive 39-year-old man presented with generalised nodular lesions. He was apyrexial and normotensive, with a normal respiratory rate. The rest of the examination was normal. He had been on antiretroviral therapy for $>4$ years; most importantly, he was on a secondline regimen (lopinavir/ritonavir (Aluvia) based). The appearance of the lesions, together with the history, led to the following possible diagnoses: bacillary angiomatosis, cutaneous cryptococcosis, nodular Kaposi sarcoma or cutaneous histoplasmosis.

S Afr Med J 2015;105(10):874. DOI:10.7196/SAMJnew.8766
\end{abstract}

An HIV-positive 39-yearold man presented with generalised nodular lesions (Figs 1 - 4). He was apyrexial and normotensive, with a normal respiratory rate. The rest of the examination was normal. He had been on antiretroviral therapy for $>4$ years; most importantly, he was on a second-line regimen (lopinavir/ritonavir (Aluvia) based). The appearance of the lesions, along with the history, led to the following possible diagnoses: bacillary angiomatosis, cutaneous cryptococcosis, nodular Kaposi sarcoma or cutaneous histoplasmosis.

Investigations revealed the following:

- absolute CD4 count: $15 \times 10^{6} / \mathrm{L}$ (500 - 2010$)$

- HIV viral load: 1764 copies/mL

- blood cultures: aerobic and anaerobic negative

- full blood count: normocytic anaemia, with haemoglobin: $8 \mathrm{~g} / \mathrm{dL}(14.3-18.3)$

- urea and electrolytes: normal

- liver function test: normal

- calcium, magnesium and phosphate: normal

- urine microscopy culture and sensitivity: negative

- sputum for GeneXpert for tuberculosis: negative

- bone marrow trephine biopsy: multifactorial cause of anaemia, no obvious infiltrates

- skin biopsy - vascular proliferative lesions in keeping with Bartonella, substantiated by a polymerase chain reaction (PCR)

- tissue culture: no growth

- chest radiography: normal.

A diagnosis of bacillary angiomatosis is clinical and can be confirmed by serology, blood culture and histology. ${ }^{[1-3]}$ It is difficult to culture Bartonella $;^{[1,2]}$ serology cannot

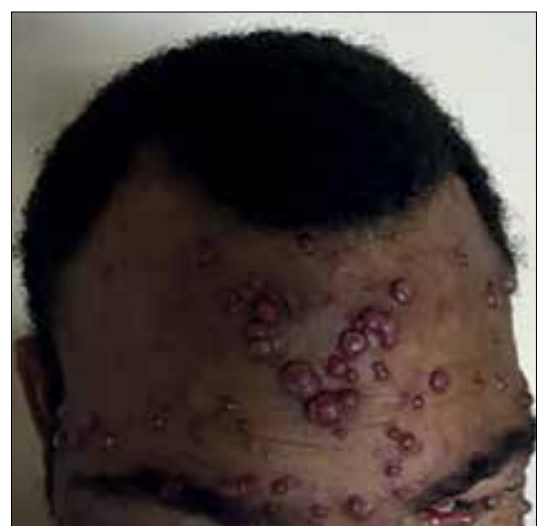

Fig. 1. Bacillary angiomatosis lesions on the forehead.

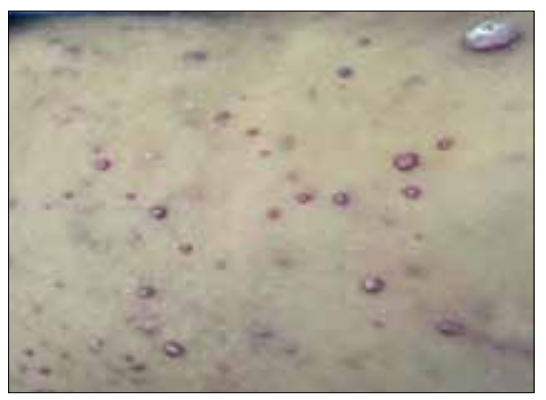

Fig. 2. Bacillary angiomatosis lesions on the back.

differentiate between species. ${ }^{[1,2]}$ WarthinStarry silver staining is the gold standard for diagnosis, revealing clusters of bacilli. ${ }^{[1,2]}$

Vascular proliferative lesions are typical histological features. ${ }^{[1,2]}$ In our case, however, Warthin-Starry silver staining did not reveal the bacilli; therefore, tissue was sent for PCR testing, which confirmed the diagnosis. Nested PCR yielded 19 positive results from 188 specimens from HIV-positive patients. ${ }^{[4]}$ After being treated with erythromycin and rifampicin for 1 month, our patient's lesions regressed.

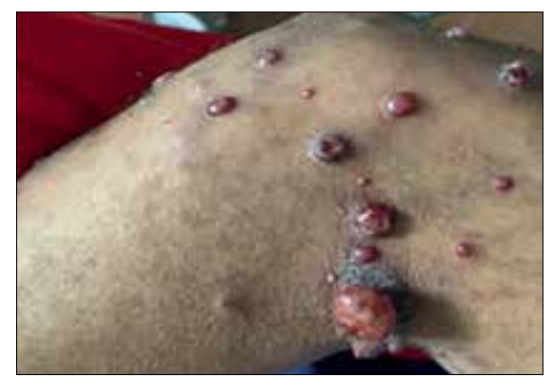

Fig. 3. Vascular lesions of bacillary angiomatosis on the right elbow.

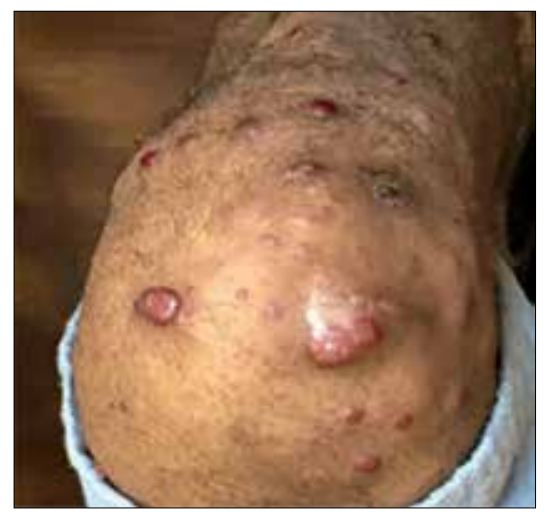

Fig. 4. Vascular lesions of bacillary angiomatosis on the right knee.

\section{Discussion}

There are $>30$ different species of Bartonella, ${ }^{[1,2]}$ of which 13 have been isolated in humans. ${ }^{[1,2]}$ Bartonella species are fastidious, facultative, intracellular, slowgrowing Gram-negative bacteria that cause a broad spectrum of diseases in humans. ${ }^{[1]}$ The two most commonly associated with HIV are B. quintana and B. henselae. ${ }^{[1,2,5]}$ Transmission of Bartonella to humans occurs via a cat scratch that is contaminated with Bartonella-infected fleas. ${ }^{[1,2,5,6]}$ The prevalence of Bartonella in HIV-positive persons is reported to be very 
low. ${ }^{[1,2,6]}$ Various organs or systems may be involved in Bartonella infection, ranging from skin, subcutaneous tissue, bones, mucosa, central nervous system, lymph nodes, liver and spleen..$^{[1,2,7-10]}$ Unspecific manifestations, such as bacteraemia, endocarditis and unexplained fever, have also been reported. ${ }^{[1,2]}$

\section{References}

1. Longo D, Fauci A, Kasper DL, et al., eds. Harrison's Principles of Internal Medicine. 18th ed. New York: McGraw-Hill, 2011

2. Goldman L, Schafer AI. Goldman's Cecil Medicine. 24th ed. New York: Saunders, 2012.

3. Koehler JE, Sanchez MA, Garrido CS, et al. Molecular epidemiology of Bartonella infections in patients with bacillary angiomatosis-peliosis. N Engl J Med 1997;337(26):1876-1883.
4. Frean J, Arndt S, Spencer D. High rate of Bartonella henselae infection in HIV-positive outpatients in Johannesburg, South Africa. Trans R Soc Trop Med Hyg 2002;96:549-550.

5. Tappero JW, Perkins BA, Wenger JD, et al. Cutaneous manifestations of opportunistic infections in patients infected with human immunodeficiency virus. Clin Microbiol Rev 1995;8(3):440-450.

6. Plettenberg A, Lorenzen T, Burtsche BT, et al. Bacillary angiomatosis in HIV-infected patients - an

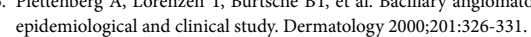

Kopidemiological and clinical study. Dermatology 2000;201:326-331. 7. Koehler JE, Quinn FD, Berger TG, et al. Isolation of Rochalimaea spe
lesions of bacillary angiomatosis. N Engl J Med 1992;327:1625-1631.

lesions of bacillary angiomatosis. N Engl J Med 1992;327:1625-1631.
Perkocha LA, Geaghan SM, Yen TSB, et al. Clinical and pathological features of bacillary peliosis 8. Perkocha LA, Geaghan SM, Yen TSB, et al. Clinical and pathological features of bacillary peliosis
hepatis in association with human immunodeficiency virus infection. N Engl J Med 1990;323:1586. hepatis in association with human immunodeficiency virus infection. N Engl I Med 1990;323:1586. with human immunodefiency virus. Ann Intern Med 1992;116:740-742.

0. Mohle-Boetani JC, Koehler JE, Berger TG, et al. Bacillary angiomatosis and bacillary peliosis in patients infected with human immunodeficiency virus: Clinical characteristics in a case-control study. Clin Infect Dis 1996;22:794-800. 